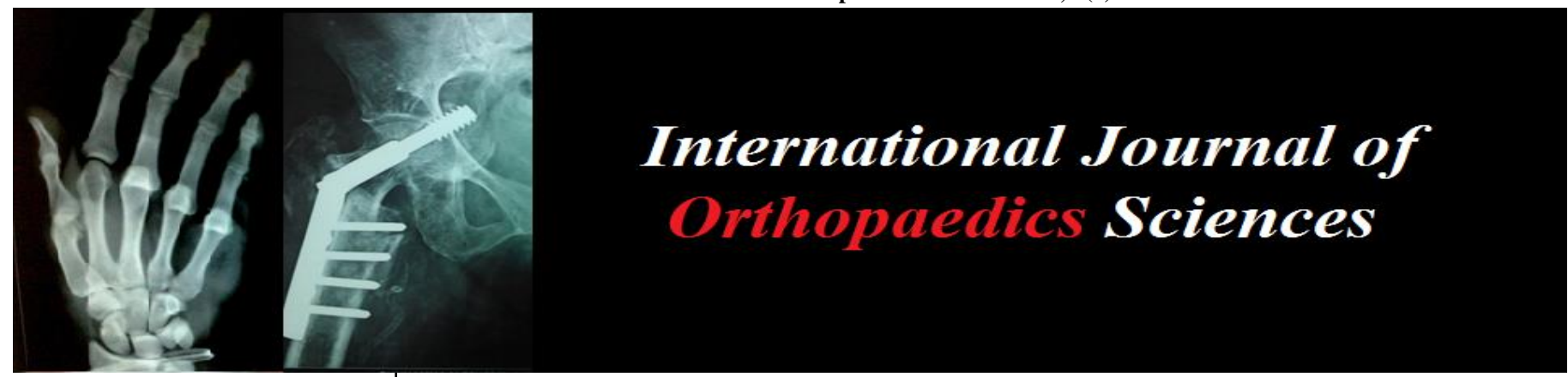

E-ISSN: 2395-1958

P-ISSN: 2706-6630

IJOS 2020; 6(1): 157-161

(C) 2020 IJOS

www.orthopaper.com

Received: 19-11-2019

Accepted: 23-12-2019

Dr. Venkat Rama Choudary

Pathuri

Assistant professor Department of orthopaedics, GSL Medical

College Rajahmundry, Andhra Pradesh, India
Corresponding Author:

Dr. Venkat Rama Choudary Pathuri

Assistant professor Department of orthopaedics, GSL Medical College Rajahmundry, Andhra Pradesh, India

\section{A comparative evaluation closed reduction with percutaneous K-wire fixation versus closed reduction of extra articulur fracture of distal end of radius}

\section{Dr. Venkat Rama Choudary Pathuri}

DOI: https://doi.org/10.22271/ortho.2020.v6.i1c.1853

\begin{abstract}
Background: Selection of method of treatment of Colles fracture depends upon age, occupation, dominant hand, type of fracture, co-morbid conditions and nature of wound. Even in the treatment of fracture in elderly patients, orthopaedic surgeon must have more thresholds for intervention in an unstable and displaced fracture than young one. There is difference in the outcome of fracture stabilisation of Colles fracture, so we have designed this study to evaluate the result of treatment of this fracture by closed reduction and plaster cast immobilisation alone or by K-wire fixation and plaster cast immobilisation.
\end{abstract}

Material and Method: As per exclusion and inclusion criteria 64 patients with fracture of distal and of radius were enrolled for this study and equally divided into two groups. Patients were assessed clinically for range of movement, fracture union and by radiologically for radiological parameters like, volar tilt which was expressed as degree from neutral position radial inclination and radial length. The range of movement was measured and compared to the normal side after 3 months for assessment of daily life activities Gartland and wereley score was used, in the form of excellent, good, fair and poor.

Result: Overall evaluation the result was excellent in $2(6.25 \%)$ patient in group A and $4(12.5 \%)$ in group B. It was good in $6(18.75 \%)$ patents in group A and $18(56.25 \%)$ patients is group B. $20(62.5 \%)$ patients in group A have fair result and $10(31.25 \%)$ patient in group B have fair result. Result was poor in $4(12.5 \%)$ patient in group A and $1(3.125 \%)$ in group B.

Conclusion: The overall evaluation result of two modalities of treatment, K-wire fixation has statistically significant better result than cast immobilisation alone. More patient in $\mathrm{K}$ - wire group has good result $(56.25 \%)$ then closed reduction group but in closed reduction group fair result was more $(62.5 \%)$.

Keywords: Colles fracture, K-wire fixation, closed reduction, outcome

\section{Introduction}

In April issue of Edinburgh medical and surgical journal 1814, Colles A, a professor of Anatomy and surgery in Royal College of surgeons in Ireland, has published an article on the fracture of the carpal extremity of the radius. Details of clinical presentation, non operative reduction and difficulties in the reduction were discussed in details. This fracture of carpal extremities of the radius is called Colles fracture by his name. ${ }^{[1]}$ Fracture of the distal end of radius accounts for $18 \%$ of all fracture above $65 \mathrm{yrs}$ and because of increase in geriatric population the incidence is going to increase. Incidence is more in women than men ${ }^{[2,3]}$. Many fracture of the distal end of the radius are relatively uncomplicated but the fracture that are unstable and osteoporotic, are challenges. In these condition the goal of orthopaedic surgeon is to restore the functional anatomy by a method in such a way that will not compromise the overall function of the hand ${ }^{[4,5]}$. There are a number of methods available for immobilisation and treatment of these fractures which includes conservative management with cast immobilisation, closed reduction and transulnar pinning, transradial pinning or Kapandiji intrafocal pinning. Closed reduction with external fixation, open reduction with different approach using suitable implant. ${ }^{[6]}$

Selection of method of treatment depends upon age, occupation, dominant hand, type of fracture, co-morbid conditions and nature of wound. Even in the treatment of fracture in elderly patients, orthopaedic surgeon must have more thresholds for intervention in an unstable 
and displaced fracture than young one. ${ }^{[7]}$

There are various risk factors which are responsible for instability and subsequent complication. Most important among them are intra articular involvement, associated ulnar fracture, dorsal comminution beyond the mid axial plane of radius, shortening of the radius more than $6 \mathrm{~mm}$ and primary displacement with dorsal angulations more than 20 degree.

There is difference in the outcome of fracture stabilisation of Colles fracture, so we have designed this study to evaluate the result of treatment of this fracture by closed reduction and plaster cast immobilisation alone or by $\mathrm{K}$-wire fixation and plaster cast immobilisation.

Primary objective of this study is to compare the result of this two method of treatment with respect to volar tilt (distal articular surface) radius height restoration and radial inclination. Secondary objective is compare the efficacy of the two treatment modality with respect to movement of the wrist.

\section{Material and Method}

Present study is a prospective comparative study conducted in two centres from July 2017 to October 2019.

\section{Selection of cases}

Patients with radiologically confirmed fracture of the distal end of radius were included in this study based on exclusion and inclusion criteria.

\begin{tabular}{|c|c|}
\hline Inclusion on criteria & Exclusion criteria \\
\hline Both sex & Paediatric patient \\
Extra articular fracture & $\begin{array}{c}\text { Intra articular compo and fracture } \\
\text { Metabolic disorder and bony deformity. }\end{array}$ \\
\hline
\end{tabular}

\section{Calculation of sample size}

Based on incidence of fracture and confidence interval $85 \%$ the sample size was calculated to be 64 , they were randomly divided into two groups, group A and group B having 32 patient in each group. Group A patients were treated with closed reduction with cast and group B patients were treated by closed reduction with percutaneous K-wire and cast application.

\section{Ethics}

Present study is approved by institutional ethics committee and written informed consent was taken from patient before enrolling them in this study.

\section{Method}

After admission history of nature of fall and severity of injury was taken and examined thoroughly. Patients were examined for deformity inflammation, bony irregularity, relative position of radial and ulnar styloid process. Movements of the wrist were evaluated. Vascularity was accessed and plaster last was applied. All routine investigation was done. Radiological assessment of injured arm was done by AP and lateral view, the parameters like radial inclination, length, and palmer tilt was noted.

For closed reduction and cast application we used standard procedure, under continuous longitudinal traction the fracture was disimpacted and there was increase in dorsal angulations, this was followed by the reducing hand forces the distal fragment to the volar side under continuous traction, at the mean time stabilizing hand holds the proximal radius, the result of the reposition is maintained by pronating the distal fragment and traction was stopped, this ends the manoeuvre. [7] A Plaster cast was applied extending from below elbow to metacarpal head, palmer flexion and ulnar deviation was maintained.

For surgical technique in group B first reduction of fracture was done and checked by fluoroscopy, once satisfactory reduction was achieved, under general anaesthesia K-wire of $1.5 \mathrm{~mm}$ size was pierced, through radial styloid process and the medial cortex of the proximal fragment. Once satisfactory reduction was achieved which was confirmed by $\mathrm{C}$-arm, the plaster cast was opposed with wrist in natural position.
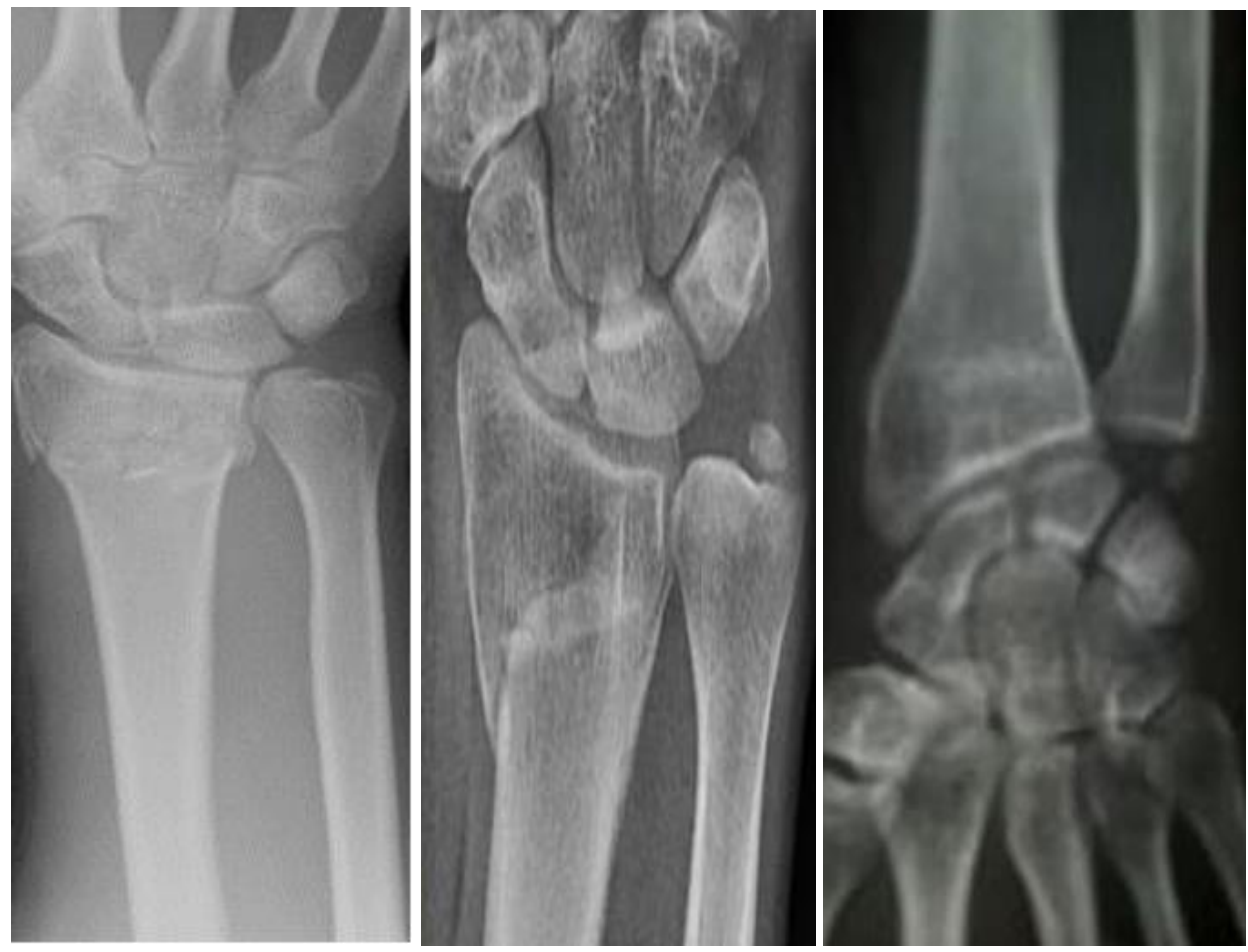

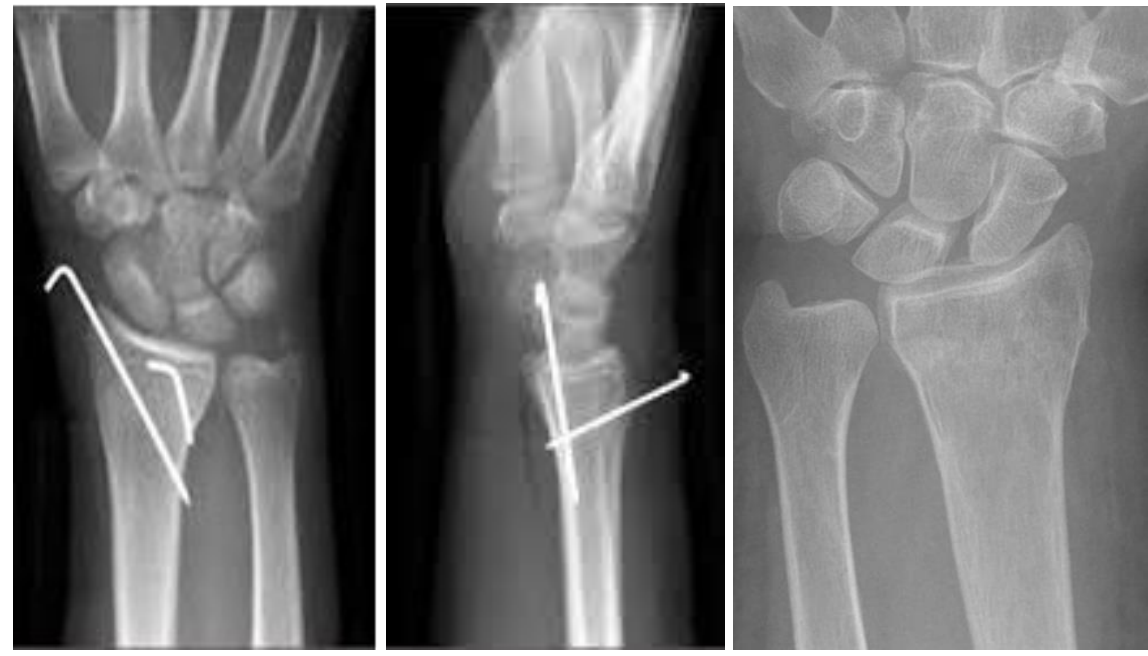

Fig: Fracture distal end of radius with closed reduction and k-wire fixation

For post operative pain, inflammation and infection, anti inflammatory analgesic and antibiotic was used. Post operative X-ray was done to confirm the reduction and displacement if any. After 6 weeks cast and K- wire was removed and patients were assessed clinically for range of movement, fracture union and by radiologically for radiological parameters like, volar tilt which was expressed as degree from neutral position radial inclination and radial length. The range of movement was measured and compared to the normal side after 3 months for assessment of daily life activities Gartland and wereley score was used, in the form of excellent, good, fair and poor.

\section{Result}

As per exclusion and inclusion criteria 64 patients with fracture of distal and of radius were enrolled for this study and equally divided into two groups. Patient of group A were treated with closed reduction and cost immobilisation and group B were treated with percutaneous $\mathrm{K}$ - wise and cast immobilisation.

Table 1: Demography of the patients in two groups

\begin{tabular}{|c|c|c|c|c|}
\hline \multicolumn{2}{|c|}{ Variables } & Group A Number (\%) & Group B Number (\%) & P value \\
\hline \multirow{5}{*}{ Age } & $>30$ yrs & $2(6.25 \%)$ & $1(3.125 \%)$ & \multirow{5}{*}{0.8038 chi-square statistic 1.6275} \\
\hline & $31-40$ yrs & $2(6.25 \%)$ & $4(12.5 \%)$ & \\
\hline & $41-50$ yrs & $6(18.75 \%)$ & $4(12.5 \%)$ & \\
\hline & $51-60$ yrs & $6(18.75 \%)$ & $6(18.75 \%)$ & \\
\hline & $>60 \mathrm{yrs}$ & $14(43.75 \%)$ & $17(53.125 \%)$ & \\
\hline \multirow{2}{*}{$\operatorname{sex}$} & Male & $14(43.75 \%)$ & $15(46.875 \%)$ & \multirow{2}{*}{0.8017 chi square statistic 0.0631} \\
\hline & Female & $18(56.25 \%)$ & $17(53.125 \%)$ & \\
\hline \multirow{2}{*}{ Side of injury } & Right & $22(68.75 \%)$ & $20(62.5 \%)$ & \multirow{2}{*}{0.598 chi square statistic 0.2771} \\
\hline & Left & $10(31.25 \%)$ & $12(37.5 \%)$ & \\
\hline \multirow{2}{*}{ Moge of injury } & RTA & $2(6.25 \%)$ & $2(6.25 \%)$ & \multirow{2}{*}{0.545 chi square statistic 0.3657} \\
\hline & Fall on out streach hands & $24(75 \%)$ & $26(81.25 \%)$ & \\
\hline \multirow{2}{*}{ Type of fracture } & $\mathrm{I}$ & $22(68.75 \%)$ & $24(75 \%)$ & \multirow{2}{*}{0.578185 chi statistic 0.3092} \\
\hline & II & $10(31.25 \%)$ & $8(25 \%)$ & \\
\hline
\end{tabular}

As per table-1 out of 64 patients 3 patients (4.68\%) were below 30 yrs of age. 6 patients $(9.375 \%)$ were between 31 to 40 hours of age, $10(15.625 \%)$ were between 41to 50yrs, 12 $(18.75 \%)$ were between 51 to $60 \mathrm{yrs}$ of age and remaining 31 $(48.43 \%)$ were above 60yrs. The $\mathrm{P}$ value was 0.80 , which is not significant statistically. In group A there was 14 male and 18 female and group B there was 15 male and 17 female, the $P$ value was 0.80 , which is not significant statistically. In group A right side was effected in $22(68.75 \%)$ patients and left side was effected in 10 (31.25\%). Similar in group B right side was affected in 20 patients and left side was affected in 10 patients, The $\mathrm{P}$ value was 0.598 which is not significant. In group A mode of injury was RTA in $8(25 \%)$ patients and 24 (75\%) patient in group A has fall on outstretched hand. In Group B mode of injury by RTA was in $6(18.75 \%)$ patients and fall on outstretched hand was 26 patients $(81.25 \%)$. TypeI fracture was present in $22(68.75 \%)$ patients in group A and $24(75 \%)$ in group B. Type-II fracture was present in 10 $(31.25 \%)$ in group A and $8(25 \%)$ in group B.

Table 2: Outcome of the treatment two groups

\begin{tabular}{|c|c|c|c|c|}
\hline \multicolumn{2}{|c|}{ Variables } & Group A Number $(\%)$ & Group B Number $(\%)$ & P value \\
\hline \multirow{3}{*}{ Radiological parameters } & Radial length $(\mathrm{mm})$ & $9.28 \pm 0.730$ & $11.124 \pm 1.1074$ & 0.0001 \\
\cline { 2 - 5 } & Radial inclination & $20.30 \pm 1.89$ & $22.875 \pm 3.60$ & 0.0001 \\
\cline { 2 - 5 } & Volar tilt & $4.01 \pm 0.52$ & $6.70 \pm 0.607$ & $65.43 \pm 6.871$ \\
Range of movement & Palmer flexion & $60.81 \pm 9.33$ & $63.46 \pm 3.32$ & 0.0001 \\
\cline { 2 - 5 } & Dorsi flexion & $62.42 \pm 6.32$ & $68.44 \pm 6.342$ & 0.04 \\
\cline { 2 - 5 } & Supination & $63.94 \pm 7.370$ & $63.9 \pm 7.02$ & 0.001 \\
\cline { 2 - 5 } & Pronation & $62.01 \pm 5.112$ & 0.02 \\
\hline
\end{tabular}




\begin{tabular}{|l|c|c|c|}
\hline \multirow{5}{*}{ Complicate } & Ulnar derivation & $23.22 \pm 2.312$ & $24.36 \pm 3.012$ \\
\cline { 2 - 4 } & Radial derivation & $17.01 \pm 1.82$ & $18.2 \pm 2.11$ \\
\hline \multirow{4}{*}{} & Infection & 0 & $2(6.25 \%)$ \\
\cline { 2 - 4 } & Malunion & $4(12.50 \%)$ & $1(3.125 \%)$ \\
\cline { 2 - 4 } & Stiffness of wrist & $3(9.375 \%)$ & $1(3.125 \%)$ \\
\cline { 2 - 4 } & Residual pain & $6(18.75 \%)$ & $1(3.125 \%)$ \\
\cline { 2 - 4 } & Reduced grip strength & $8(25 \%)$ & $1(3.125 \%)$ \\
\hline
\end{tabular}

As per table -2 regarding outcome of the treatment, radial length mean value was $9,28+0.730 \mathrm{~mm}$ in group $\mathrm{A}$ and $11.124+1.10 \mathrm{~mm}$ in group $\mathrm{B}$, the $\mathrm{P}$ value was less than 0.0001 , which is highly significant, The radial inclination was $20.30 \pm 189$ degree in group A and $22.875+3.60$ degree in group B. The $\mathrm{P}$ value was 0.0001 which is significant statistically. The Volar tilt was $4.01 \pm 0.52$ degree in group A and 7.70+0.607 degree in group B. The $\mathrm{P}$ value was less than 0.0001 . Regarding range of movement the mean of palmer flexion was $60.81 \pm 9.33$ degree in group $\mathrm{A}$ and $65.43 \pm 68.71$ degree in group $\mathrm{B}$, dorsi flexion was $62.42 \pm 6.32$ degree in group $\mathrm{A}$ and $63.46 \pm 3.31$ degree in group $\mathrm{B}$. The supination was $63.94 \pm 7.370$ degree in group A and $68.44 \pm 6.32$ degree in group B.

The pronation was $62.01 \pm 5.112$ degree in group $\mathrm{A}$ and $63.9 \pm 7.02$ degree in group B. ulnar deviation was 23.22 2.312 degree in group A and 24.36 +3.012 degree in group B. Radial deviation mean was $17.01 \pm 1.82$ degree in group $A$ and $18.2 \pm 2.11$ degree in group B. This difference in range of movement was significant statistically as $\mathrm{P}$ value was $<0.05$. With respect to complication in both group infection was present in 2 patients in group B but absent in group A, malunion was present in 4 patients in group $A$ and 1 patient in group B. Stiffness of wrist was present in 3 patients in group $\mathrm{A}$ and 1 patient in group B. Residual pain was there in 6 $(18.75 \%)$ patient in group A but only 1 patient in group B. Reduced grip strength was present in $8(25 \%)$ patient in group $A$ and 1 (3.125) in group B but these findings are not significant statistically.

Table 3: Over all evaluation of result

\begin{tabular}{|c|c|c|c|}
\hline Variables & $\begin{array}{c}\text { Group A } \\
\text { number }(\%)\end{array}$ & $\begin{array}{c}\text { Group B } \\
\text { number }(\%)\end{array}$ & $P$ value \\
\hline Excellent & $2(6.25 \%)$ & $41(3.125 \%)$ & \multirow{4}{*}{$\begin{array}{l}0.008 \text { chi square } \\
\text { statistic } 11.7874\end{array}$} \\
\hline Good & $6(18.75 \%)$ & $18(56.25 \%)$ & \\
\hline Fair & $20(62.5 \%)$ & $10(31.25 \%)$ & \\
\hline Poor & $4(12.5 \%)$ & $1(3.125 \%)$ & \\
\hline
\end{tabular}

As per table-3 regarding overall evaluation the result was excellent in $2(6.25 \%)$ patient in group A and $4(12.5 \%)$ in group B. It was good in $6(18.75 \%)$ patents in group A and 18 $(56.25 \%)$ patients is group B. $20(62.5 \%)$ patients in group A have fair result and $10(31.25 \%)$ patient in group B have fair result. Result was poor in $4(12.5 \%)$ patient in group A and 1 $(3.125 \%)$ in group B.

\section{Discussion}

During one year three month of study 64 patients were enrolled for this study having radio logically confirmed fracture of distal end of radius. It has been observed that three patients were below 30yrs of age but most of the patients were above $60 y$ rs of age. There was female predominance; this finding is supported by the work of Baron JA et al ${ }^{[2]}$ and Baron et al $^{[3]}$. Right side injury was more common than the left side, that is $(54.68 \%$ vs $45.31 \%)$, Bagul et al has reported (56.66\% vs $43.37 \%$ ) which support our finding, Leung et al has reported that right side fracture is $61.11 \%$ in right side which support our study. ${ }^{[9,10]}$ fall on out stretched hand was more common made of injury than. Rood traffic accident (RTA) This finding corroborates with the finding of venkatesh RR et al ${ }^{[11]}$ and Aggarwal A ${ }^{[12]}$ et al. Type I fracture was more common than Type -2 fracture which is supported by work of Bagul RR et al and Agarwal et al ${ }^{[9,12]}$ Regarding variables of the outcome of treatment, the radiological parameter, the radial length was significantly longer in K- wire fixation group than closed reduction group. The radial inclination was significantly more in $\mathrm{K}$ - wire fixation group. Volar tilt was also significaltly more in k-wire group. This finding corroborates with the finding of venkatesh RR et al. ${ }^{[11]}$ So $\mathrm{K}$-wire fixation group has better and statically significant anatomical reduction. This finding is supported by the work of Panthi s et al and stein AHJr et al $[13,14]$. We have observed that there was significant difference in the range of movement in two group which is supported by the work of Mohamaed F et al and Venkatesh RB et al. ${ }^{[11,15]}$ Range of movement like palmer flexion, dorsal flexion, supination and pronation, ulnar deviation and redial deviation are significantly better in $\mathrm{K}$-wire fixation group. Venkatesh $\mathrm{RB}$ et al has also found the same but the difference was not significant statistically. The complication was less is $\mathrm{K}$-wire group but it was not significant this finding is supported by the work of Gills et al ${ }^{[16]}$. The residual pain and reduced grip strength was more common in closed reduction and cast application group.

The overall evaluation result of two modalities of treatment, $\mathrm{K}$-wire fixation has statistically significant better result than cast immobilisation alone. This finding is supported by the work of Baba Anetal and Venkatesh RB et al [11, 17]. More patient in K- wire group has good result (56.25\%) then closed reduction group but in closed reduction group fair result was more $(62.5 \%)$. This finding corroborates with the work of Kumar p et al.

\section{Conclusion}

To conclude K-wire fixation is associated with better anatomical reduction as observed radiologically. Range of movement like palmer flexion, dorsal flexion, supination and pronation, ulnar deviation and redial deviation are significantly better in K-wire fixation group. The overall evaluation result of two modalities of treatment, K-wire fixation better result than closed reduction.

\section{References}

1. Colles A. On the fracture of the carpal extremity of the radius. Edin Med Surg J. 1814; 10:182.

2. Baron JA, Karagas M, Barrett $\mathbf{J}$ et al. Basic epidemiology of fractures of the upper and lower limb among Americans over 65 years of age. Epidemiology. 1996; 7:612-618.

3. Brogren E, Petranek M, Atroshi I. Incidence and characteristics of distal radius fractures in a southern Swedish region. BMsC Musculoskelet Disord. 2007; 8:48.

4. Ring D, Jupiter JB. Treatment of osteoporotic distal 
radius fractures. Osteoporos Int. 2005; 16(2):S80-S84

5. Simic PM, Weiland AJ. Fractures of the distal aspect of the radius: changes in treatment over the past two decades. Instr Course Lect. 2003; 52:185-195.

6. Blakeney WG. Stabilization and treatment of Colles' fractures in elderly patients. Clin Interv Aging. 2010; 5:337-344. Published 2010 Nov 18. doi:10.2147/CIA.S1 0042 .

7. Charnley J. Die konservative Therapie der Extremita Ètenfrakturen. Berlin Heidelberg New York: Springer, 1968.

8. Gartland JJ JR, Werley CW. Evaluation of healed Colles' fracture. J Bone Joint Surg Am. 1951; 33:895-907.

9. Bagul RR, Deshmukh A, Salgia A, Agarwal T, Rajani D, Sooknundan M. Comparative evaluation in the measurement of the radial height, radial inclination, and ulnar variance in fracture distal end radius treated conservatively by closed reduction and cast and closed reduction, Kirschner wire and cast. Med J DY Patil Univ. 2014; 7:590-5.

10. Leung KS, Shen WY, Leung PC, Kinninmonth AW, Chang JC, Chan GP. Ligamentotaxis and bone grafting for comminuted fractures of the distal radius. $J$ Bone Joint Surg. 1989; 71:838-42.

11. Venkatesh RB, Maranna GK, Narayanappa RK. A Comparative Study between Closed Reduction and Cast Application Versus Percutaneous K- Wire Fixation for Extra-Articular Fracture Distal end of Radius. J Clin Diagn Res. 2016; 10(2):RC05-RC9. doi:10.7860/JCDR/2 016/18266.7220.

12. Aggarwal A, Rastogi A. External fixation for intra articular fracture distal end radius- a prospective study between bridging and non-bridging fixator. Indian $\mathbf{J}$ Orthop, 2004; 38:23-7.

13. Panthi $\mathrm{S}$, Khatri $\mathrm{K}$, Kharel $\mathrm{K}$ et al. Radiological and Functional Outcome of Displaced Colles' Fracture Managed with Closed Reduction and Percutaneous Pinning: A Prospective Study. Cureus. 2017; 9(1):e960. Published 2017 Jan 6. doi:10.7759/cureus.960.

14. Stein AH JR, Katz SF. Stabilization of comminuted fractures of the distal inch of the radius: percutaneous pinning._http://journals.lww.com/corr/Citation/1975/0500 0/Stabilization_of_Comminuted_Fractures_of_the.28.asp x Clin Orthop Relat Res. 1975; 108:174-181.

15. Mohamed F. Mostafa Treatment of distal radial fractures with antegrade intra-medullary Kirschner wires Mostafa, M.F. Strat Traum Limb Recon. 2013; 8:89. https://doi.or g/10.1007/s11751-013-0161-z.

16. Gill S, Raj M, Singh S, Rajpoot A, Mittal A, Yadav N. Intra-articular fracture distal end radius external fixation versus locking volar radius plate: A comparative study. J Orthop Traumatol Rehabil. 2019; 11:31-43.

17. Baba AN, Shah NA, Seth S, Aejaz S, Badoo AR, Kangoo KA. Role of percutaneous pinning and cast application in extra-articular and simple intra-articular management of distal radius fractures: A clinical study. J Orthop Traumatol Rehabil. 2017; 9:6-11.

18. Kumar P, Kisan D. Percutaneous kirschner wire fixation of displaced colles' fracture. J Orthop Traumatol Rehabil. 2018; 10:98-102. 